\title{
TrkB Receptors Modulation of Glutamate Release Is Limited to a Subset of Nerve Terminals in the Adult Rat Hippocampus
}

\author{
Daniela B. Pereira, ${ }^{1}$ Nelson Rebola, ${ }^{2}$ Ricardo J. Rodrigues, ${ }^{2}$ Rodrigo A. Cunha, ${ }^{2}$ \\ Arsélio P. Carvalho, ${ }^{1}$ and Carlos B. Duarte ${ }^{1 \star}$ \\ ${ }^{1}$ Department of Zoology, Center for Neuroscience and Cell Biology, University of Coimbra, \\ Coimbra, Portugal \\ ${ }^{2}$ Faculty of Medicine, Center for Neuroscience and Cell Biology, University of Coimbra, Coimbra, \\ Portugal
}

Brain-derived neurotrophic factor (BDNF) modulates glutamatergic excitatory transmission in hippocampal primary cultures by acting at a presynaptic locus. Although it has been suggested that BDNF also modulates adult hippocampus glutamatergic transmission, this remains a matter of controversy. To clarify a putative role for this neurotrophin in the modulation of glutamate release we applied exogenous BDNF to isolated adult rat hippocampal nerve terminals. BDNF, at 100 $\mathrm{ng} / \mathrm{ml}$, potentiated by $25 \%$ the $\mathrm{K}^{+}$-evoked release of $\left[{ }^{3} \mathrm{H}\right]$ glutamate from hippocampal synaptosomes. The small effect of BDNF on $\left.{ }^{3} \mathrm{H}\right]$ glutamate release correlated with a modest increase in phospholipase $\mathrm{C} \gamma$ (PLC $\gamma$ ) phosphorylation, and with the lack of effect of BDNF on extracellular-signal regulated kinase (ERK) and Akt phosphorylation. Immunocytochemistry studies demonstrated that only about one-third of glutamatergic synaptosomes were positive for TrkB immunoreactivity. Furthermore, biotinylation and subsynaptic fractionation studies showed that only one-fourth of total full-length TrkB was present at the plasma membrane, evenly distributed between the presynaptic active zone and the postsynaptic density. These results indicate that BDNF modulates synaptic transmission presynaptically in a small subset of hippocampal glutamatergic synapses that contain TrkB and that express the receptor on the plasma membrane. @ 2006 Wiley-Liss, Inc.

Key words: BDNF; hippocampal synaptosomes; presynaptic TrkB; rat

Neurotrophins are recognized currently as important modulators of synaptic plasticity in central and peripheral nervous systems in addition to their role in neuronal differentiation and survival (Schuman, 1999; Poo, 2001). Particular attention has been given to the hippocampus because it is a prominent site of expression of BDNF and NT-3 and their receptors (Ernfors et al., 1990; Klein et al., 1990; Lamballe et al., 1991). The physiological actions of BDNF, a well established modulator of hippocampal synaptic transmission, are mediated by the high-affinity receptor tyrosine kinase $\operatorname{TrkB}$, and the low affinity pan-neurotrophin receptor p75 (Chao, 2003). BDNF binding to TrkB leads to the activation of the ERK, the phosphatidylinositol 3-kinase (PI3-K) and the PLC $\gamma$ pathways, which transduce most of the cellular responses to BDNF (Huang and Reichardt, 2003).

Studies in hippocampal primary cultures show that exogenously applied BDNF enhances the evoked and spontaneous excitatory synaptic transmission (Lessmann et al., 1994; Levine et al., 1995). Although a postsynaptic contribution to this effect has been suggested (Levine et al., 1995, 1998), a predominant presynaptic action has been demonstrated convincingly in cultured hippocampal neurons (Lessmann and Heumann, 1998; Li et al., 1998a,b; Berninger et al., 1999; Schinder et al., 2000). A recent study showed that early presynaptic and late postsynaptic components contribute independently to BDNFinduced synaptic plasticity in dissociated cultures of hippocampal neurons (Alder et al., 2005).

In contrast, in hippocampal preparations from mature animals, the effect of BDNF on excitatory synaptic transmission remains a matter of controversy. An early

Abbreviations: ACPD, (1S,3R)-1-aminocyclopentane-1,3-dicarboxylic acid; BDNF, brain-derived neurotrophic factor; BCA, bicinchoninic acid; BSA, bovine serum albumin; DOC, deoxycholic acid; DTT, dithiothreitol; ECF, enhanced chemifluorescence; ERK, extracellular-signal regulated kinase; FBS, fetal bovine serum; LTP, long-term potentiation; NT-3, neurotrophin-3; PBS, phosphate-buffered saline; PLC $\gamma$, phospholipase $\mathrm{C} \gamma$; PMSF, phenylmethylsulphonylfluoride; PVDF, polyvinylidene difluoride; SDS, sodium dodecyl sulfate; SDS-PAGE, SDS-polyacrylamide gels; TBS, Tris-buffered saline.

Contract grant sponsor: Fundação para a Ciência e a Tecnologia; Contract grant sponsor: Fundação Calouste Gulbenkian.

*Correspondence to: Carlos B. Duarte, Center for Neuroscience and Cell Biology, Department of Zoology, University of Coimbra, 3004-517 Coimbra, Portugal. E-mail: cbduarte@ci.uc.pt

Received 30 July 2005; Revised 29 November 2005; Accepted 12 December 2005

Published online 13 February 2006 in Wiley InterScience (www. interscience.wiley.com). DOI: 10.1002/jnr.20784 
study using acutely dissociated hippocampal slices showed that superfusion with BDNF induces a long lasting potentiation of excitatory synaptic transmission in the CA1 area, acting at a presynaptic locus (Kang and Schuman, 1995). Other groups have been unable to reproduce these results (Figurov et al., 1996; Patterson et al., 1996; Tanaka et al., 1997; Frerking et al., 1998; Gottschalk et al., 1998). It has been suggested that low penetration of BDNF into the slice tissue due to different rates of neurotrophin application is the underlying reason for this discrepancy (Kang et al., 1996). Nonetheless, superfusion rates cannot solely account for such inconsistencies because a lack of BDNF effect was also observed in studies using rapid superfusion rates (Tanaka et al., 1997; Frerking et al., 1998). A lasting enhancement of synaptic transmission by BDNF in the dentate gyrus "in vivo" was also reported (Messaoudi et al., 1998), but this was demonstrated to occur, at least partially, through postsynaptic mechanisms (Messaoudi et al., 2002; Ying et al., 2002). Accordingly, stimulation of dentate gyrus synaptosomes with BDNF did not affect $\mathrm{KCl}$-evoked glutamate release. In this study, however, a synergistic effect was observed between the neurotrophin and (1S,3R)ACPD [(1S,3R)-1-aminocyclopentane-1,3dicarboxylic acid], a metabotropic glutamate receptor agonist, in the potentiation of depolarization-evoked glutamate release (Gooney and Lynch, 2001).

BDNF has been implicated more convincingly in hippocampal long-term potentiation (LTP). BDNF knockout mice show severe impairments in LTP in the CA1 region that can be rescued by application of exogenous BDNF or by virus-mediated BDNF gene transfer (Korte et al., 1996; Patterson et al., 1996). Scavenging of endogenous BDNF or genetically engineered reduction of TrkB levels also leads to deficits in hippocampal LTP (Figurov et al., 1996; Minichiello et al., 1999; Xu et al., 2000). It has been suggested that BDNF plays a permissive role in this event by maintaining an appropriate number of docked vesicles at the active zone, thus preventing synaptic fatigue (Figurov et al., 1996; Pozzo-Miller et al., 1999; Tartaglia et al., 2001). An instructive role for BDNF in LTP induction has also been supported by recent reports (Kossel et al., 2001), and is consistent with BDNF expression and release in response to activity in the hippocampus (Patterson et al., 1992; Goodman et al., 1996; Hartmann et al., 2001).

Due to the existing controversy on whether BDNF acts presynaptically to modulate excitatory synaptic transmission in the adult hippocampus, we used purified nerve terminals obtained from adult rats to directly test if this neurotrophin modulated the evoked release of glutamate. In parallel, we also monitored if BDNF activated its established intracellular signaling pathways in isolated nerve terminals.

\section{MATERIALS AND METHODS}

\section{Materials}

Fatty acid free bovine serum albumin (BSA) and K-252a were obtained from Calbiochem-Novabiochem Intl. (La Jolla, CA). Reagents used in immunoblotting experiments were purchased from Bio-Rad (Hercules, CA). $\left[{ }^{3} \mathrm{H}\right]$ Glutamate (specific activity, $45 \mathrm{Ci} / \mathrm{mmol}$ ), polyvinylidene difluoride (PVDF) membranes, alkaline phosphatase-linked secondary antibodies, enhanced chemifluorescence (ECF) reagent, and Percoll were obtained from Amersham Biosciences (Buckinghamshire, England). The rabbit polyclonal antibody against dually phosphorylated ERK was purchased from Promega (Madison, WI). The mouse anti-TrkB antibody was from BD Biosciences Europe (Erembodegem, Belgium), rabbit anti-TrkB was from Santa Cruz Biotechnology (Santa Cruz, CA), and mouse antiTrk (E7) was from Zymed (Carlsbad, CA). The rabbit antiphospho-Akt (Ser 473), anti-phospho-PLC $\gamma$ (Tyr 783), and anti-phospho-Trk (Tyr 490) antibodies were from Cell Signaling Technology (Beverly, MA). Anti-VGluT1 and antiVGluT2 guinea pig antibodies were obtained from Chemicon (Temecula, CA). Rabbit anti-syntaxin $1 \mathrm{~A}$ was a gift by Dr. Juan Blasi (Universitat de Barcelona, Barcelona, Spain). The Alexa Fluor secondary antibodies and the Prolong Antifade mounting medium were purchased from Molecular Probes Europe BV (Leiden, The Netherlands). EZ-link sulfo-NHSSS-biotin and UltraLink Plus immobilized streptavidin were obtained from Pierce (Rockford, IL). The Microcon YM-3 centrifugal filter device, used to concentrate protein samples, was from Millipore Corporation, (Bedford, MA). BDNF was granted by Regeneron Pharmaceuticals Inc. (Tarrytown, NY). All other reagents were from Sigma Chemical Co. (St. Louis, MO) or from Merck KGaA (Darmstadt, Germany).

\section{Isolation of Crude $\left(\mathrm{P}_{2}\right)$ and Purified Hippocampal Synaptosomal Fractions}

The crude synaptosomal $\mathrm{P}_{2}$ fraction from male Wistar rat hippocampi was isolated as described elsewhere (McMahon et al., 1992; Pereira et al., 2002). Briefly, hippocampi of 6- to 8 -week-old animals were dissected and homogenized $(5 \%, \mathrm{w} / \mathrm{v})$ in $0.32 \mathrm{M}$ sucrose, $10 \mathrm{mM}$ HEPES, $\mathrm{pH} 7.4$ (sucrose buffer), using a Thomas B homogenizer. The suspension was centrifuged at 3,000 $\times g_{\max }$ for $2 \mathrm{~min}$, and the supernatants were spun at $14,600 \times g_{\max }$, for $12 \mathrm{~min}$. The upper white layer of the pellet $\left(\mathrm{P}_{2}\right)$ was removed and resuspended in sucrose buffer. Alternatively, a purified hippocampal synaptosomal suspension was isolated using the Percoll method described elsewhere (Dunkley et al., 1986) with some modifications (Pereira et al., 2002). The whole $P_{2}$ pellet was resuspended in sucrose buffer and layered on top of Percoll discontinuous gradients (23\%, $10 \%$, and 3\% Percoll in sucrose buffer for immunoblots and biotinylation experiments, or in $0.32 \mathrm{M}$ sucrose, $1 \mathrm{mM}$ EDTA, and $0.25 \mathrm{mM}$ dl-dithiothreitol for immunocytochemistry). After centrifugation at $36,500 \times g_{\max }$, for $5 \min \left(\right.$ or $25,000 \times g_{a v}$ for $11 \mathrm{~min}$, for immunocytochemistry experiments) the purified synaptosomal fraction was removed (23\%/10\% Percoll interface) and resuspended in $15 \mathrm{vol}$ of sucrose buffer or HEPES buffer (in $\mathrm{mM}, 140 \mathrm{NaCl}, 5 \mathrm{KCl}, 5 \mathrm{NaHCO}_{3}, 1.2 \mathrm{NaH}_{2} \mathrm{PO}_{4}, 1.2$ $\mathrm{MgCl}_{2}, 10$ glucose, 10 HEPES, $\mathrm{pH}$ 7.4; for immunocytochemistry). Percoll was removed by spinning twice at $30,500 \times g_{\max }$, for $20 \mathrm{~min}$ (or once at $20,000 \times g_{a v}$, for $11 \mathrm{~min}$, in the case of the immunocytochemistry experiments). The alternative protocol used for the immunocytochemistry experiments allowed us to obtain purified synaptosomes less contaminated with postsynaptic structures. The whole procedure was carried out at $0-4^{\circ} \mathrm{C}$. 


\section{Hippocampal Cell Culture}

Hippocampal primary neurons were isolated and maintained as described previously (Almeida et al., 2005). Briefly, hippocampi from E18-E19 Wistar rat embryos were dissected in $\mathrm{Ca}^{2+}$ - and $\mathrm{Mg}^{2+}$-free Hank's balanced salt solution (HBSS; in $\mathrm{mM}, 137 \mathrm{NaCl}, 5.36 \mathrm{KCl}, 4.16 \mathrm{NaHCO}_{3}, 0.44 \mathrm{KH}_{2} \mathrm{PO}_{4}$, $0.34 \mathrm{Na}_{2} \mathrm{HPO}_{4} \cdot 2 \mathrm{H}_{2} \mathrm{O}, 5$ glucose, supplemented with $1 \mathrm{mM}$ sodium pyruvate, $10 \mathrm{mM}$ HEPES, and 0.001\% phenol red, $\mathrm{pH}$ 7.4), and incubated with $0.9 \mathrm{mg} / \mathrm{ml}$ trypsin, for $15 \mathrm{~min}$ at $37^{\circ} \mathrm{C}$, in HBSS containing $0.5 \mathrm{mg} / \mathrm{ml}$ deoxyribonuclease I. Cells were washed in HBSS with $10 \%$ fetal bovine serum (FBS) and mechanically dissociated with a pipette in HBSS. Hippocampal neurons were maintained in serum-free Neurobasal medium supplemented with B27 supplement, $0.5 \mathrm{mM}$ glutamine, $0.12 \mathrm{mg} / \mathrm{ml}$ gentamycin, and $25 \mu \mathrm{M}$ glutamate, at a density of $90 \times 10^{3}$ cells $/ \mathrm{cm}^{2}$, and kept for $7-8$ days at $37^{\circ} \mathrm{C}$ in a humidified incubator with $5 \% \mathrm{CO}_{2} / 95 \%$ air.

\section{$\left[{ }^{3} \mathrm{H}\right]$ Glutamate Release}

The release of $\left[{ }^{3} \mathrm{H}\right]$ glutamate was carried out as described previously (Rodrigues et al., 2005). In short, $\mathrm{P}_{2}$ synaptosomes were washed once with KHR medium (composed of the following [in $\mathrm{mM}$ ]: $140 \mathrm{NaCl}, 1$ EDTA, $5 \mathrm{KCl}, 5 \mathrm{glu}-$ cose, and 10 HEPES, $\mathrm{pH} 7.4$ ), and resuspended in a $\mathrm{Na}^{+}{ }_{-}$salt solution (containing [in $\mathrm{mM}$ ]: $124 \mathrm{NaCl}, 3 \mathrm{KCl}, 1.25$ $\mathrm{NaH}_{2} \mathrm{PO}_{4}, 25 \mathrm{NaHCO}_{3}, 2 \mathrm{MgSO}_{4}, 2 \mathrm{CaCl}_{2}$, and 10 glucose, $\mathrm{pH} 7.4$ ), which was gassed with a $95 \% \mathrm{O}_{2}$ and $5 \% \mathrm{CO}_{2}$ mixture. The nerve terminals were equilibrated at $37^{\circ} \mathrm{C}$ for $10 \mathrm{~min}$, loaded with $0.2 \mu \mathrm{M}\left[{ }^{3} \mathrm{H}\right]$ glutamate for $5 \mathrm{~min}$ at $37^{\circ} \mathrm{C}$, washed, layered over Whatman GF/C filters, and superfused (flow rate, $0.8 \mathrm{ml} / \mathrm{min}$ ) with $\mathrm{Na}^{+}$-salt solution for $20 \mathrm{~min}$ before starting collection of the superfusate. The synaptosomes were stimulated with $20 \mathrm{mM} \mathrm{KCl}$ (isomolar substitution of $\mathrm{NaCl}$ by $\mathrm{KCl}$ in the salt solution) for $30 \mathrm{sec}$, at 3 and 9 min after starting sample collection $\left(\mathrm{S}_{1}\right.$ and $\left.\mathrm{S}_{2}\right)$, triggering a release of tritium in a $\mathrm{Ca}^{2+}$-dependent manner that is mostly glutamate (Lopes et al., 2002). When the effect of BDNF was tested the neurotrophin was added $2 \mathrm{~min}$ before $\mathrm{S}_{2}$ onward, and its effect was quantified by the modification of the $\mathrm{S}_{2} / \mathrm{S}_{1}$ ratio versus control (i.e., absence of BDNF).

\section{Immunoblotting}

Purified synaptosomes ( $2 \mathrm{mg}$ protein/ml) were pre-incubated for $40 \mathrm{~min}$ at $37^{\circ} \mathrm{C}$ in incubation medium, followed by incubation in reaction medium at $37^{\circ} \mathrm{C}$ for $5 \mathrm{~min}$ (control). BDNF was added for 1,4 , or $30 \mathrm{~min}$. The reaction was stopped by adding $2 \times$ sample buffer $(100 \mathrm{mM}$ Tris, $100 \mathrm{mM}$ glycine, 4\% sodium dodecyl sulfate [SDS], $8 \% \beta$-mercaptoethanol, $8 \mathrm{M}$ urea, $3 \mathrm{mM}$ sodium orthovanadate, and $0.001 \%$ bromophenol blue), and heating the samples for $5 \mathrm{~min}$ at $95^{\circ} \mathrm{C}$. Hippocampal neurons in culture were stimulated for 15 or $30 \mathrm{~min}$ with BDNF before ending the reaction by washing in ice-cold $\mathrm{PBS} / \mathrm{Ca}^{2+}$ / $\mathrm{Mg}^{2+}$ (phosphate-buffered saline with $1 \mathrm{mM} \mathrm{CaCl}_{2}$ and $0.5 \mathrm{mM}$ $\left.\mathrm{MgCl}_{2}\right)$ and lysing the cells with supplemented RIPA buffer (150 mM NaCl, $50 \mathrm{mM}$ Tris, 5 mM EGTA, 1\% Triton, 0.5\% deoxycholic acid [DOC], 0.1\% SDS, pH 7.5, supplemented with proteinase inhibitors $[1 \mu \mathrm{g} / \mathrm{ml}$ chymostatin, leupeptin, antipain, and pepstatin, CLAP, and $100 \mu \mathrm{M}$ PMSF] and $1 \mathrm{mM}$ dithiothre- itol [DTT]). After one freeze-thaw cycle, lysates were centrifuged at $16,100 \times g_{\max }$ during $10 \mathrm{~min}$ at $4^{\circ} \mathrm{C}$, to remove solid debris, and denatured for $5 \mathrm{~min}$ at $95^{\circ} \mathrm{C}$ in $2 \times$ sample buffer (125 mM Tris, $100 \mathrm{mM}$ glycine, 4\% SDS, $200 \mathrm{mM}$ DTT, 20\% glycerol, $3 \mathrm{mM}$ sodium orthovanadate. and 0.001\% bromophenol blue). Equal amounts of protein $(10-30 \mu \mathrm{g})$, as determined by the bicinchoninic acid (BCA) method (Smith et al., 1985), were separated by electrophoresis on 6 or $10 \%$ SDS-polyacrylamide gels (SDS-PAGE), and transferred electrophoretically to polyvinylidene difluoride (PVDF) membranes. These were blocked for $1 \mathrm{hr}$ at room temperature, in Tris-buffered saline (137 mM NaCl, $20 \mathrm{mM}$ Tris- $\mathrm{HCl}, \mathrm{pH}$ 7.6) containing $0.1 \%$ Tween 20 (TBS-T) and 5\% low fat milk. Incubation with the primary antibodies (anti-active ERK1/2 1:5,000, anti-phosphoAkt [Ser473] 1:1,000 and anti-phospho-Trk [Tyr 490] 1:1,000 in TBS-T 1\% low fat milk; anti-phospho-PLC 1 1:750 in TBS-T $5 \%$ BSA) was carried out overnight at $4^{\circ} \mathrm{C}$ or for $1 \mathrm{hr}$ at room temperature. After extensive washing, the membranes were incubated with an alkaline phosphatase-linked secondary antibody (1:20,000 in TBS-T 1\% low fat milk). Protein immunoreactive bands were visualized by ECF on a Storm 860 Gel and Blot Imaging System (Amersham Biosciences), after incubation of the membranes with ECF reagent for $5 \mathrm{~min}$.

\section{Biotinylation Experiments}

Plasma membrane synaptosomal proteins were biotinylated essentially as described previously (Gomes et al., 2004). Synaptosomes purified by Percoll gradients ( $2 \mathrm{mg}$ protein $/ \mathrm{ml}$ ) were pre-incubated for $40 \mathrm{~min}$ at $37^{\circ} \mathrm{C}$ in incubation medium. After a 5 -min incubation in reaction medium at $37^{\circ} \mathrm{C}$, synaptosomes were pelleted and placed on ice. The nerve terminals were resuspended in ice-cold $\mathrm{PBS} / \mathrm{Ca}^{2+} / \mathrm{Mg}^{2+}$ containing $1 \mathrm{mg} / \mathrm{ml}$ sulfo-NHS-SS-biotin, and incubated for $30 \mathrm{~min}$ at $4^{\circ} \mathrm{C}$. Synaptosomes were washed twice in PBS/ $\mathrm{Ca}^{2+} / \mathrm{Mg}^{2+}$ with $100 \mathrm{mM}$ glycine to remove the excess of biotin, and washed once again in PBS $/ \mathrm{Ca}^{2+} / \mathrm{Mg}^{2+}$. Supplemented RIPA buffer was used to lyse the nerve terminals following the same procedure described above for hippocampal neurons. The lysates were precipitated twice with UltraLink Plus immobilized streptavidin beads for $2 \mathrm{hr}$ at $4^{\circ} \mathrm{C}$, to confirm that all biotinylated protein was precipitated. Streptavidin precipitates were washed with RIPA buffer and eluted with sample buffer $(62.5 \mathrm{mM}$ Tris, $50 \mathrm{mM}$ glycine, 2\% SDS, 100 $\mathrm{mM}$ DTT, $10 \%$ glycerol, $1.5 \mathrm{mM}$ sodium orthovanadate and $0.0005 \%$ bromophenol blue). The supernatants were concentrated by centrifugation at $13,500 \times g_{\max }$ for $1 \mathrm{hr} 45 \mathrm{~min}$ at $4{ }^{\circ} \mathrm{C}$ in Microcon YM-3 centrifugal filter devices, or left in the original concentration. After denaturation, the whole volume of the precipitates and the concentrated supernatant, or one-eighth of the total volume of the supernatant in the original concentration, were loaded and separated in 6\% SDSPAGE and immunoblotted as described above with the mouse anti-TrkB antibody (1:750 in TBS-T 1\% low fat milk). The use of different concentrations of the supernatant allowed us to confirm the reliability of the quantification method.

\section{Subsynaptic Fractionation}

The separation of the presynaptic active zone, postsynaptic density, and non-synaptic fractions from hippocampal 



Fig. 1. BDNF potentiates $\mathrm{KCl}$-evoked glutamate release from hippocampal nerve terminals. A: Time course of tritium release from hippocampal synaptosomes subjected to two periods of depolarization (30 sec each) with $20 \mathrm{mM} \mathrm{KCl}$ (horizontal bars) separated by $6 \mathrm{~min}$. Where indicated $100 \mathrm{ng} / \mathrm{ml} \mathrm{BDNF}$ was added to the superfusate. B:

Average effect of BDNF on $\mathrm{K}^{+}$-evoked $\left[{ }^{3} \mathrm{H}\right]$ glutamate release in $\mathrm{S}_{2}$. The results are the average \pm SEM of four independent experiments, carried out using independent preparations. Statistical significance was determined using the paired Student's $t$-test. ${ }^{*} P<0.05$.

nerve terminals was carried out essentially as described initially by Phillips et al. (2001). Briefly, purified synaptosomes were diluted $1: 10$ in cold $0.1 \mathrm{mM} \mathrm{CaCl}$. An equal volume of $2 \times$ solubilization buffer ( $2 \%$ Triton X-100, $40 \mathrm{mM}$ Tris, $\mathrm{pH} 6.0$ ) was added, and after $30 \mathrm{~min}$ of incubation on ice the resulting insoluble synaptic junctions were pelleted by spinning at $100,000 \times g_{a v}$ for $30 \mathrm{~min}$ at $4{ }^{\circ} \mathrm{C}$. The supernatant (extrasynaptic fraction) was decanted and proteins were precipitated with 6 vol of acetone at $-20^{\circ} \mathrm{C}$, and recovered by centrifugation at $18,000 \times g_{a v}$ for $30 \mathrm{~min}$ at $-15^{\circ} \mathrm{C}$. The insoluble pellet was resuspended and incubated for $30 \mathrm{~min}$ in $10 \mathrm{vol}$ of cold solubilization buffer at $\mathrm{pH} 8.0$ to promote the dissociation of the extracellular matrix and hence the separation of the presynaptic active zone from the postsynaptic density. A centrifugation step precipitated the postsynaptic density, which is insoluble at $1 \%$ Triton $\mathrm{X}-100$. The solubilized presynaptic active zone proteins, present in the supernatant, were precipitated and recovered as described for the extrasynaptic fraction. All precipitated fractions were solubilized in 5\% SDS and the protein concentration was determined by the BCA method (Smith et al., 1985). The samples were denatured with $2 \times$ sample buffer and stored at $-20^{\circ} \mathrm{C}$. The protease inhibitor PMSF was present in all extraction steps. Samples were probed with the rabbit anti-TrkB (1:500) using the immunoblotting procedure described previously.

\section{Immunocytochemistry}

Percoll purified synaptosomes were resuspended in HEPES buffer, allowed to adhere to poly-L-lysine-coated coverslips and processed for immunocytochemistry as described previously (Diaz-Hernandez et al., 2002). Briefly, synaptosomes were fixed with $4 \%$ paraformaldehyde and incubated with $0.1 \%$ Triton X-100, 3\% BSA, and 5\% calf serum in $\mathrm{PBS}$, for $1 \mathrm{hr}$ at room temperature. The coverslips were then

washed and incubated with the primary antibodies in PBS with 3\% BSA and 5\% normal rat serum (rabbit anti-TrkB 1:500, mouse anti-TrkB 1:50, guinea pig anti-VGluT1 or anti-VGluT2 1:5,000, mouse anti-synaptophysin 1:100, and rabbit anti-syntaxin 1A 1:200). After washing with 3\% BSA in PBS, the synaptosomes were incubated with Alexa 488 antirabbit, Alexa 594 anti-mouse, and Alexa 594 anti-guinea pig secondary antibodies. After the last washing steps, coverslips were mounted with Prolong Antifade mounting medium and visualized using a Zeiss Axiovert 200 inverted microscope equipped with a cooled CCD camera. The resulting images were analyzed with MetaFluor 4.0 software.

\section{Statistical Analysis}

Results are presented as means \pm SEM of the indicated number of experiments. Statistical significance was determined using two-tailed $t$-test or one-way ANOVA followed by Newman-Keuls or Dunnett post-tests, as indicated.

\section{RESULTS}

\section{BDNF Stimulates $\left[{ }^{3} \mathrm{H}\right]$ Glutamate Release From Hippocampal Nerve Terminals}

A putative role for BDNF in the modulation of glutamate release from adult rat hippocampal synaptosomes was studied using superfused nerve terminals loaded previously with $\left[{ }^{3} \mathrm{H}\right]$ glutamate. Under these conditions, depolarization with $20 \mathrm{mM} \mathrm{KCl}$ for $30 \mathrm{sec}$ was previously shown to induce $\mathrm{Ca}^{2+}$-dependent release of $\left[{ }^{3} \mathrm{H}\right]$ glutamate that represented about $90 \%$ of the total tritium released, as determined by HPLC (Lopes et al., 2002). Two consecutive stimulations with $20 \mathrm{mM} \mathrm{KCl}$ $\left(\mathrm{S}_{1}\right.$ and $\left.\mathrm{S}_{2}\right)$, separated by $6 \mathrm{~min}$, induced the release of about the same amount of glutamate, with an $\mathrm{S}_{2} / \mathrm{S}_{1}$ ratio 
A



B



independent experiments carried out using different preparations. Data is presented as mean fold increase in pTrk immunoreactivity \pm SEM. Statistical significance was determined by one-way ANOVA followed by the Dunnett comparison test, comparing each BDNF stimulated condition with the control. $* P<0.05$, $* * P<0.01$. of $0.92 \pm 0.03(n=4)$. When synaptosomes were superfused with BDNF $(100 \mathrm{ng} / \mathrm{ml})$ for $2 \mathrm{~min}$ before the second depolarization pulse with $\mathrm{KCl}\left(\mathrm{S}_{2}\right)$ there was a significant $(P<0.05)$ increase in the evoked release of $\left[{ }^{3} \mathrm{H}\right]$ glutamate, to $125.6 \pm 6.0 \%$ of the control (Fig. 1). These results indicate that BDNF acts presynaptically to modulate glutamate release.

\section{BDNF Activates TrkB But Does Not Significantly Activate ERK or Akt in Hippocampal Nerve Terminals}

To confirm the presence of BDNF-sensitive Trk receptors in hippocampal synaptosomes, denatured samples of Percoll purified nerve terminals, incubated with BDNF for 1, 4, or $30 \mathrm{~min}$, were probed with anti-phospho-Trk (Tyr 490) antibody, which recognizes the activated form of Trk receptors (Fig. 2). BDNF, at the concentration of $100 \mathrm{ng} / \mathrm{ml}$, increased TrkB phosphorylation by about four-fold after just $1 \mathrm{~min}$ of incubation, and to more than six-fold after 4 and $30 \mathrm{~min}$. These results show that TrkB can be phosphorylated and hence activated in response to BDNF in hippocampal nerve terminals.

We next investigated whether TrkB phosphorylation in response to BDNF resulted in the activation of downstream signaling pathways. BDNF-stimulated purified nerve terminals were probed for their content on the phosphorylated forms of ERK1/2, Akt and PLC $\gamma$ (Fig. 3, pERK, pAkt, and pPLC $\gamma)$. A certain level of ERK phosphorylation was found for both isoforms (ERK1/p44 and ERK2/p42) in control conditions (Fig. 3A), using an antibody against the dually phosphorylated (presumably active) form of ERK, as previously demonstrated in hippocampal synaptosomes (Pereira et al., 2002). BDNF, at $100 \mathrm{ng} / \mathrm{ml}$, was unable to significantly increase ERK1/2


Fig. 3. BDNF activates PLC $\gamma$ but is without effect on the phosphorylation of ERK and Akt in hippocampal synaptosomes. Percoll purified synaptosomes were incubated with $100 \mathrm{ng} / \mathrm{ml} \mathrm{BDNF}$ for 1 , 4, or $30 \mathrm{~min}$ and probed for their content in the phosphorylated forms of ERK1/2 (pERK), Akt (pAkt), and PLC $\gamma$ (pPLC) (A). The quantitative analysis of 3-10 independent experiments for each set of immunoblots, carried out in different preparations: (B) phosphorylation of ERK2, (C) PLC $\gamma$, (D) Akt. Data is presented as mean fold increase in phosphorylation \pm SEM. Statistical significance was determined by oneway ANOVA followed by the Dunnett comparison test $\left({ }^{*} P<0.05\right.$, $* * P<0.01)$. Unless otherwise indicated, comparisons were made between indicated conditions and the control condition.

phosphorylation (Fig. 3B). Quantitative results are shown only for the ERK2 isoform because phosphorylation of both isoforms varied in a similar manner. Akt phosphorylation, which occurs downstream of PI3-K activation, was not significantly affected by incubating nerve terminals with BDNF for several durations, as shown in the repre- 
A

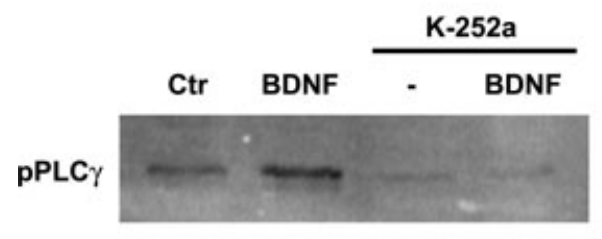

Fig. 4. K-252a inhibits BDNF-induced PLC $\gamma$ phosphorylation. Purified synaptosomes were incubated with $100 \mathrm{ng} / \mathrm{ml} \mathrm{BDNF}$ for $4 \mathrm{~min}$ in the presence or absence of $200 \mathrm{nM} \mathrm{K}-252 \mathrm{a}$ (applied $10 \mathrm{~min}$ before BDNF application). A: Representative immunoblot against pPLC $\gamma$. B: Quantification of three independent immunoblots obtained using
B



different preparations. Data is presented as mean fold activation \pm SEM and statistical significance was determined by one-way ANOVA followed by Dunnett comparison test between each condition and the control condition (Ctr). ${ }^{* *} P<0.01$.
A

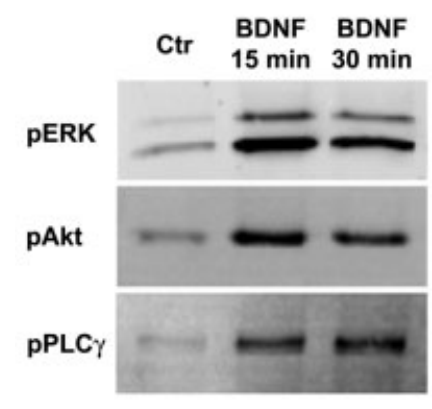

B

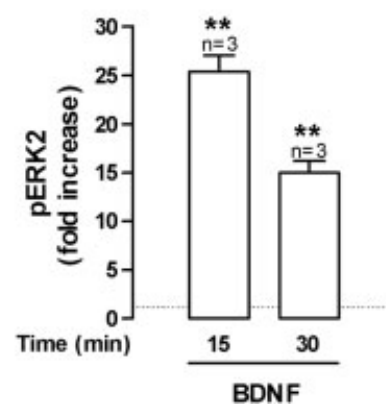

C

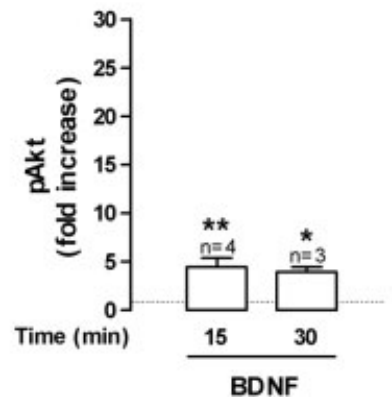

D

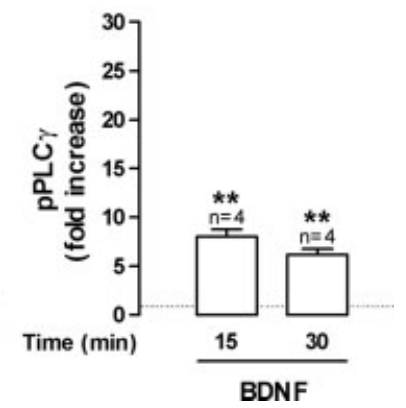

Fig. 5. BDNF extensively activates the ERK, PI3-K and PLC $\gamma$ pathways in hippocampal primary cultures. Hippocampal neurons were stimulated for 15 or $30 \mathrm{~min}$ with $100 \mathrm{ng} / \mathrm{ml} \mathrm{BDNF}$ as described in Materials and Methods. A: Representative blots of three to four independent experiments for pERK, pAkt, and pPLC $\gamma$ detection. Quantitative results for the phosphorylation of ERK $(\mathbf{B})$, Akt $(\mathbf{C})$,

and PLC $\gamma(\mathbf{D})$ induced by BDNF, are shown as mean fold increase in phosphorylation \pm SEM, for the indicated number of experiments carried out in different preparations. Statistical significance was determined by one-way ANOVA followed by Dunnett comparison test between each condition and control condition. ${ }^{*} P<0.05$, $* * P<$ 0.01 .

To confirm that the BDNF used in these studies sentative blot (Fig. 3A) and in the quantitative analysis plot (Fig. 3D).

In contrast to the lack of effect of BDNF on ERK and Akt signaling pathways, PLC $\gamma$ phosphorylation increased approximately two-fold after a 4-min incubation of hippocampal synaptosomes with $100 \mathrm{ng} / \mathrm{ml} \mathrm{BDNF}$ (Fig. 3A,C), and slightly decreased thereafter (Fig. 3A, C; BDNF $30 \mathrm{~min}$ ). BDNF-induced PLC $\gamma$ activation in hippocampal synaptosomes was completely abolished by the Trk kinase inhibitor K-252a, at the concentration of $200 \mathrm{nM}$ (Berg et al., 1992; Tapley et al., 1992) (Fig. 4A,B). This suggests that PLC $\gamma$ phosphorylation in response to BDNF was indeed mediated by the TrkB receptor. was able to activate all TrkB initiated signaling pathways in a different system, we probed BDNF-stimulated hippocampal neuron cultures for pERK, pAkt, and pPLC $\gamma$. BDNF induced Akt phosphorylation (approximately 5and 4-fold, for 15 and $30 \mathrm{~min}$ stimulation, respectively; Fig. 5A,C) and massive phosphorylation of ERK (approximately 25- and 15-fold for 15 and $30 \mathrm{~min}$ stimulation, respectively; Fig. 5A,B) in cultured hippocampal neurons. In the same cell culture, PLC $\gamma$ phosphorylation was increased by eight- and six-fold, after 15- and 30min incubations with BDNF, respectively (Fig. 5A,D). These results confirm that the BDNF used in this study was capable of fully inducing the activation of the ERK, 


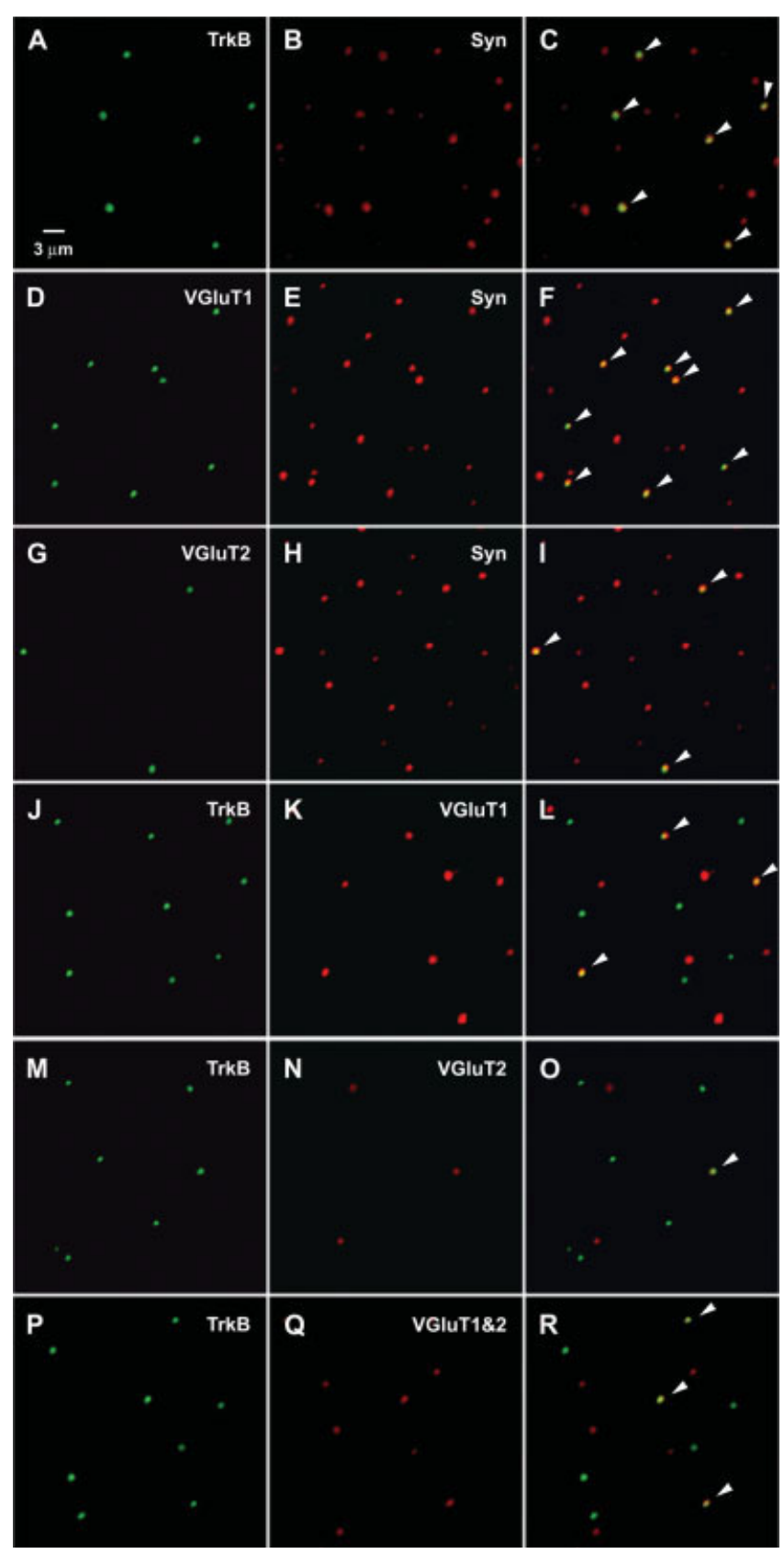

Fig. 6. TrkB is present in less than one-third of synaptophysin- or VGluT-positive nerve terminals. Percoll purified synaptosomes were plated on poly-L-lysine-coated coverslips, processed for immunocytochemistry and visualized by fluorescence microscopy as described in Materials and Methods. Representative images of three to eight independent experiments are shown. Each row of three panels represents a doublestaining experiment, where the third panel depicts the merge of the previous two. Synaptosomes showing co-localization of both red and green fluorescence are marked by arrowheads. Synaptophysin (Syn), TrkB, VGluT1, and VGluT2 immunoreactivities are indicated in each panel.

Akt and PLC $\gamma$ pathways in cultured hippocampal neurons. The comparison of the amplitude of the BDNFinduced activation of these signaling pathways in cultured neurons and purified synaptosomes suggests that the effects
TABLE I. Quantification of the Fraction of Adult Hippocampal Nerve Terminals (Total or Glutamatergic) Expressing TrkB and of the Total Amount of Synaptic TrkB Present in Glutamatergic Hippocampal Synaptosomes ${ }^{\star}$

\begin{tabular}{lc}
\hline Structure & $\%$ \\
\hline Synaptophysin-positive structures containing: & \\
$\quad$ VGluT1 & $35.3 \pm 6.5$ \\
VGluT2 & $14.9 \pm 7.3$ \\
VGluT1 and 2 & $39.5 \pm 5.4$ \\
TrkB-positive structures containing: & \\
VGluT1 & $38.3 \pm 4.4$ \\
VGluT2 & $13.0 \pm 2.5$ \\
VGluT1 and 2 & $52.4 \pm 4.6$ \\
Synaptophysin & $95.4 \pm 2.6$ \\
Structures containing TrkB: & \\
VGluT1 & $31.9 \pm 2.1$ \\
VGluT2 & $25.7 \pm 3.5$ \\
VGluT1 and 2 & $31.2 \pm 3.2(n=8)$ \\
Synaptophysin & $29.2 \pm 3.3(n=6)$ \\
\hline
\end{tabular}

$\star$ All values are mean \pm SEM of the experiments, and are the quantification of the data represented in Figure 6. $n=3$ experiments unless indicated.

of BDNF are minimal in the overall population of hippocampal nerve terminals, correlating with the small effect on glutamate release in nerve endings.

\section{TrkB Is Absent in More Than Two-Thirds of Adult Hippocampal Glutamatergic Nerve Terminals}

The small effect of BDNF on KCl-evoked glutamate release, and in stimulating $\operatorname{TrkB}$ downstream signaling pathways in hippocampal synaptosomes lead us to examine the percentage of nerve terminals that are endowed with TrkB in the adult hippocampus. Synaptosomes were plated on poly-L-lysine-coated coverslips and processed for immunocytochemistry as described in Materials and Methods. Antibodies against synaptophysin (Fig. 6) and syntaxin 1A (data not shown), presynaptic vesicle and plasma membrane proteins, respectively, were used as presynaptic markers. TrkB receptors were labeled with two different anti-TrkB antibodies that recognize the full-length and the truncated forms of the receptor (Fig. 6 and data not shown). As shown in Figure $6 \mathrm{~A}-\mathrm{C}$, rabbit anti-TrkB and mouse anti-synaptophysin staining co-localized partially (arrowheads in Fig. 6C). However, a quantification of these images showed that approximately $70 \%$ of synaptophysinlabeled structures lacked TrkB labeling (Table I). Similar results were obtained with rabbit anti-syntaxin $1 \mathrm{~A}$ and mouse anti-TrkB antibodies (data not shown). These data suggest that only about one-third of presynaptic terminals in the adult rat hippocampus are endowed with $\operatorname{TrkB}$ receptors.

It is important to realize that $>90 \%$ of TrkB-labeled structures were also synaptophysin-positive (Fig. 6A-C, Table I). This suggests that this purified synaptosomal preparation is mostly devoid of postsynaptic contaminating structures, or that TrkB receptors are confined to nerve terminals at the synapse. The former hypothesis seems 
likely because staining with an anti-PSD-95 antibody did not yield any significant signal (data not shown).

We next investigated the presence of TrkB in glutamatergic presynaptic terminals. The VGluT1 and VGluT2 isoforms of vesicular glutamate transporters have been used as glutamatergic nerve terminal markers because: 1) all glutamatergic synapses, possess either VGluT1 or VGluT2 (Fremeau et al., 2001); 2) the presence of VGluT1 or VGluT2 in non-glutamatergic neurons is sufficient to define a glutamatergic phenotype (Takamori et al., 2000, 2001); and 3) VGluT1 and VGluT2 are predominantly located at nerve terminals, in synaptic vesicles, with few or no overlap (Herzog et al., 2001).

As expected, VGluT1 and VGluT2 strongly co-localized with synaptophysin (Fig. 6D-I, arrowheads). Moreover, about $35 \%$ and $15 \%$ of synaptophysin-positive structures were VGluT1- and VGluT2-positive, respectively (Fig. 6F,I, Table I), confirming that most hippocampal glutamatergic nerve terminals express VGluT1. The amount of synaptophysin-positive structures containing VGluT1 was not significantly different from the amount of synaptophysin-positive structures containing either VGluT1 or VGluT2 (approximately 40\%; Table I; $P>0.05$, as determined by one-way ANOVA with Bonferroni test). These results suggest that approximately $40 \%$ of adult hippocampal nerve terminals are glutamatergic and that a fraction of these glutamatergic terminals express both VGluT1 and VGluT2.

Only about one-third of VGluT1-containing terminals and one-fourth of VGluT2-immunoreactive ones were TrkB-positive (Fig. 6J-O, Table I). The results shown in Figure 6J-O were obtained using the rabbit anti-TrkB antibody and they were reproduced using two other antiTrk antibodies (the mouse anti-Trk [E7] and the mouse anti-TrkB; data not shown). When all glutamatergic terminals were stained by using anti-VGluT1 and anti-VGluT2 antibodies, simultaneously, we observed that TrkB was present in approximately one-third of them (Fig. 6P-R, Table I). Among the whole population of TrkB-positive structures, close to $40 \%$ were VGluT1-positive and about 10\% were VGluT2-positive (Fig. 6J-O, Table I), whereas approximately $50 \%$ were labeled with either VGluT1 or VGluT2 (Fig. 6P-R, Table I). These results suggest that only one-third of the adult hippocampal glutamatergic terminals express TrkB whereas only half of presynaptic TrkB is confined to glutamatergic terminals in the adult hippocampus. This may explain the small effect of BDNF on the overall glutamate release (Fig. 1) and TrkB downstream signaling, measured using the whole synaptosomal population.

\section{Full-Length TrkB Receptors Are Distributed in Pre-, Post-, and Extrasynaptic Sites and Are Mostly Located Intracellularly}

We further investigated the expression and distribution of TrkB at adult hippocampal synapses using two approaches. First, we followed a fractionation procedure described previously that allows the separation of pro- teins from the presynaptic active zone and the postsynaptic density from proteins present in other parts of the synapse. Second, we determined the percentage of TrkB receptors located at the plasma membrane and at intracellular locations in hippocampal synaptosomes, by tagging extracellular proteins with biotin.

Subsynaptic fractionation was carried out by extracting synaptosomes sequentially with $1 \%$ Triton X-100 at $\mathrm{pH} 6.0$ followed by $\mathrm{pH}$ 8.0. Triton $\mathrm{X}-100$ solubilizes most synaptosomal components with the exception of the "synaptic junction," which contains the presynaptic active zone, the postsynaptic density, and interlinked transmembrane adhesion molecules. The presynaptic active zone is then solubilized by increasing the $\mathrm{pH}$ to 8.0 (Materials and Methods; Phillips et al., 2001). This procedure has been shown previously to separate pre-, post-, and extrasynaptic markers with over 90\% efficiency (Pinheiro et al., 2003; Rebola et al., 2003). Full-length (p145) and truncated TrkB (p95) showed a differential distribution among the three subsynaptic fractions (Fig. 7A,B). The majority of both TrkB isoforms was found in the extrasynaptic fraction, which includes intracellular and plasma membrane proteins that are excluded from the synaptic junction. However, approximately $35 \%$ of full length TrkB was evenly distributed between the presynaptic active zone and the postsynaptic density, whereas truncated TrkB was absent from the postsynaptic density (Fig. 7A,B). A small $10 \%$ fraction of the total truncated isoform was also present at the presynaptic active zone (Fig. 7A,B).

The isolation of subsynaptic fractions showed that the majority of TrkB receptors are excluded from the synaptic junction, but it did not clarify whether they are present at the plasma membrane, away from the active zone, or at intracellular locations. To address this question, proteins located at the plasma membrane were tagged with biotin and precipitated with streptavidin beads. Biotinylated samples were precipitated twice to test for the efficiency of the process. Both precipitates and supernatants were probed for their content in TrkB. Biotinylated proteins from the first precipitation contained the full-length and truncated forms of the receptor (Fig. 7C). The second precipitation did not significantly recover any of the TrkB isoforms, confirming the efficiency of the first streptavidin precipitation (Fig. 7C). The immunoreactivity showed in the supernatant lane for p145 and p95 TrkB corresponds to oneeighth of the total immunoreactivity present in the supernatant because only one-eighth of the total volume was probed (Fig. 7C). In some cases, the supernatant samples were concentrated by centrifugation on centrifugal filter devices so that the total volume of the supernatant could be probed. This allowed us to test for the reliability of the quantification method. We found that only about $25 \%$ of total full-length TrkB present in this synaptosomal preparation was biotinylated (Fig. 7D). However, the percentage of biotinylated truncated TrkB was significantly higher than biotinylated p145, reaching nearly 50\% (Fig. 7D).

These data indicate that the majority of TrkB present at the Percoll purified hippocampal nerve terminal preparation is located intracellularly. 
A



B

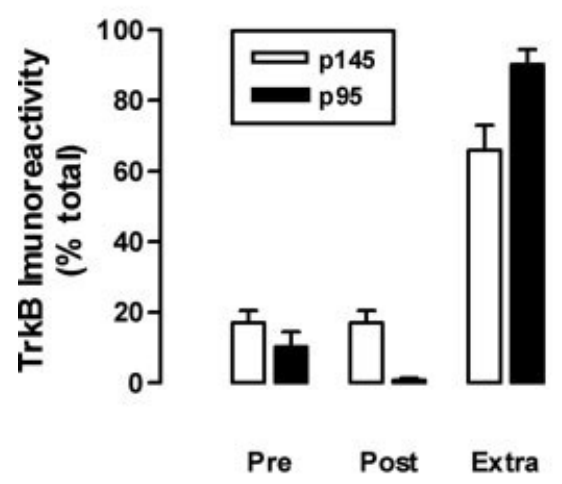

Fig. 7. Full-length TrkB localization at the adult hippocampal synapse: pre- and postsynaptic, but mostly intracellular. A,B: Subsynaptic fractionation of purified hippocampal synaptosomes was carried out as described in Materials and Methods to obtain presynaptic active zone (pre), postsynaptic density (post), and extrasynaptic (extra) fractions. These fractions were immunoblotted and probed with a rabbit anti-TrkB antibody that recognizes the full-length (p145) and the truncated (p95) form of the receptor. A representative membrane is shown in (A) whereas (B) depicts the quantification of three independent experiments. Data is presented as mean \% of total p145 or p95 TrkB immunoreactivity \pm SEM. C,D: Purified hippocampal synaptosomes were incubated with sulfo-NHS-SS-biotin to tag plasma

\section{DISCUSSION}

We present evidence supporting the presence of TrkB receptors in only about one-third of glutamatergic hippocampal nerve terminals from adult rats. This correlates with the small effect of BDNF on the phosphorylation of PLC $\gamma$ and on KCl-evoked glutamate release from the whole population of hippocampal synaptosomes. Furthermore, only $25 \%$ of full-length TrkB present in this synaptosomal preparation was located at the plasma membrane, evenly distributed among the presynaptic active zone and the postsynaptic density, further explaining the small effect of BDNF on the overall glutamate release. Taken together, however, our data suggest that BDNF may have a much stronger effect on glutamate release from the small population of terminals endowed with TrkB at the plasma membrane.

Approximately $30 \%$ of adult hippocampal glutamatergic nerve terminals, possessing simultaneously VGluT1 and VGluT2, were positive for TrkB receptors in this study. A similar result was obtained for the overall hip-



D



membrane proteins, and precipitated twice with streptavidin beads (Materials and Methods). C: Representative immunoblot showing p145 and p95 TrkB present in the total volume of the first (PP \#1) and the second ( $\mathrm{PP} \# 2$ ) precipitates, and in one-eighth of the total supernatant (S/8). D: Quantification of seven independent experiments representing the mean \% of biotinylated TrkB \pm SEM. Each experiment was carried out using a different synaptosomal preparation. Total TrkB was calculated by adding the value for precipitated TrkB to the value for supernatant TrkB multiplied by 8 . In some experiments, the total supernatant was probed, after concentrating the samples. In this case, total TrkB was calculated simply by adding precipitated and supernatant $\operatorname{TrkB}$ values.

pocampal nerve terminal preparation (Fig. 6). These are higher percentages than reported previously by Drake et al. (1999), where less than one in 200 presynaptic profiles (axons and terminals) were immunoreactive to p145 TrkB, as assessed by immunoelectron microscopy. That was considered to be an underestimation of the actual number of labeled terminals because TrkB immunoreactivity was not present in most planes of section. Because the immunocytochemistry of isolated nerve terminals allows the visualization of TrkB staining in the whole terminal, this might generate a more precise quantification of TrkB-positive terminals.

Only one-fourth of total full length TrkB was located at the plasma membrane in our purified synaptosomal preparation. Although we cannot rule out the possibility that the receptor is internalized during the preparation of synaptosomes, our findings are in agreement with a previous report showing that most TrkB receptors are located intracellularly in many regions of adult hippocampal neurons, including at nerve terminals (Drake et al., 
1999). These results do not clarify, though, the percentage of nerve terminals that express p145 TrkB at the surface. Nevertheless, these data suggest that, within the small fraction of TrkB-positive glutamatergic nerve terminals, the percentage of terminals capable of responding to BDNF may be even smaller due to the small percentage of TrkB receptors present at the plasma membrane. The amplitude of the responses to BDNF in vivo may change depending on the recent history of the terminal because plasma membrane depolarization and cAMP elevation rapidly increase the amount of TrkB receptors associated with the plasma membrane of CNS neurons (Meyer-Franke et al., 1998).

An interesting difference in the location of full length and truncated $\mathrm{TrkB}$ receptors resides in their subsynaptic distribution. Although approximately $35 \%$ of p 145 TrkB receptors were evenly distributed between the presynaptic active zone and the postsynaptic density, the truncated isoform was absent from the postsynaptic density and only $10 \%$ was present at the presynaptic active zone (Fig. 7). Because only about $25 \%$ of full-length TrkB was present at the plasma membrane, this suggests that all extrasynaptic p145 TrkB is intracellular. About half of p95 TrkB was at the plasma membrane indicating that a significant fraction of the extrasynaptic truncated isoform is located there. This confinement of the catalytically active TrkB receptor to the active zone is very interesting considering the known effects of BDNF on synaptic transmission and plasticity discussed below. The absence of the truncated receptor at the postsynaptic density, reported previously in adult rat brain (Kryl et al., 1999; Xu et al., 2000), raises the question of the precise function of $\mathrm{p} 95 \mathrm{TrkB}$ : does it work simply as a BDNF scavenger, or does it mediate a synaptic response independently of p145 TrkB, as suggested for other cellular outcomes (Baxter et al., 1997; Yacoubian and Lo, 2000; Rose et al., 2003), which is dependent on its specific location?

Application of BDNF to isolated hippocampal nerve terminals increased TrkB phosphorylation, showing that $\mathrm{TrkB}$ receptors located at the synaptosomal plasma membrane can be activated by its ligand. The lack of effect of BDNF on ERK and Akt phosphorylation in the overall nerve terminal population is probably due to the reduced number of terminals that express TrkB at the plasma membrane. Thus, the eventual ERK and Akt activation triggered by TrkB in a limited number of terminals was probably undetectable above the basal activation of these molecules in the whole population of terminals. BDNF was still able to significantly stimulate PLC $\gamma$ phosphorylation, which is interesting because PLC $\gamma$ is involved in BDNF-induced potentiation of depolarization-evoked exocytotic glutamate release in cultured cortical neurons (Matsumoto et al., 2001). This suggests that the basal phosphorylation of this protein is sufficiently low to allow the detection of an increase in phosphorylation of a small percentage of the total PLC $\gamma$.

The small fraction of glutamatergic nerve terminals that are endowed with TrkB at the plasma membrane, accessible to its specific ligands, accounts for the small effect of BDNF on the average $\left[{ }^{3} \mathrm{H}\right]$ glutamate release (about 25\% increase) from a population of hippocampal synaptosomes. This effect of BDNF was not observed in a previous study, where the effect of the neurotrophin on $\mathrm{KCl}-$ evoked release of endogenous glutamate from dentate gyrus synaptosomes was investigated, possibly due to the lower sensitivity of the method used. In this case, however, BDNF was shown to act synergistically with the metabotropic glutamate receptor agonist (1S,3R)ACPD to potentiate KCl-evoked glutamate release, to a small extent (Gooney and Lynch, 2001). These findings and our own results contrast with the large effect of BDNF on $\left[{ }^{3} \mathrm{H}\right]$ glutamate release from hippocampal synaptosomes isolated from 3-week-old rats, where the neurotrophin potentiated neurotransmitter release evoked by $\mathrm{KCl}$-depolarization to about $400 \%$ of the control (Canas et al., 2004). It would be interesting to know the percentage of TrkB-positive glutamatergic synaptosomes in developing rats, to determine whether a change in the glutamatergic nerve terminals expressing TrkB at the plasma membrane may account for the observed differences.

BDNF was also shown to potentiate 4-AP-evoked glutamate release from cerebrocortical synaptosomes in a synapsin I/II-dependent manner, probably by a mechanism involving ERK (Jovanovic et al., 2000; but see also Pereira et al., 2002). Forebrain synaptosomes of TrkB $(-/-)$ mice show reduced levels of $\mathrm{Ca}^{2+}$-dependent neurotransmitter release in response to $\mathrm{K}^{+}$-depolarization (Carmona et al., 2003). This suggests that TrkB receptors are also present in the forebrain and cerebral cortex, where they modulate glutamate release.

BDNF was also shown to induce a long-lasting potentiation of evoked field excitatory postsynaptic potentials (EPSPs) in the CA1 region by acting presynaptically (Kang and Schuman, 1995), an effect that has not been confirmed by other laboratories (Figurov et al., 1996; Patterson et al., 1996; Tanaka et al., 1997; Frerking et al., 1998; Gottschalk et al., 1998). Although field EPSPs have the contribution of more than one synapse, based on the low number of TrkB-positive glutamatergic terminals demonstrated, one would predict a certain amount of failure to occur in BDNF-induced synaptic potentiation in this system. Therefore, our findings rather support the results by others showing an increase in field EPSPs after BDNF application in only 1 of 11 experiments (Frerking et al., 1998).

Several reports demonstrate that the involvement of BDNF in Schaffer collateral-CA1 synaptic LTP is at least partially achieved through presynaptic modifications, such as the reduction of synaptic fatigue by increasing the number of docked vesicles at the active zone (Figurov et al., 1996; Pozzo-Miller et al., 1999; Tyler and Pozzo-Miller 2001; Xu et al., 2000). How does this correlate with the small percentage of glutamatergic terminals that express TrkB at the plasma membrane? A putative increase in surface TrkB could be achieved after LTP-inducing high frequency stimulation, similarly to what was described for cultured hippocampal neurons (Du et al., 2000). A recruitment of TrkB recep- 
tors to presynaptic terminals, resulting in an augmented number of TrkB-positive glutamatergic terminals would be an interesting mechanism, although no evidence suggests it so far. Another possibility would be the involvement of postsynaptic TrkB receptors in the modulation of LTP by BDNF, as previously suggested (Tyler and Pozzo-Miller, 2001; Kovalchuk et al., 2002). This would predict the existence of a BDNF/TrkB-induced retrograde messenger that would carry out the presynaptic modifications attributed to BDNF during LTP. Selective genetic ablation of $\mathrm{TrkB}$ receptors at the CA1 region does not reduce LTP, however, suggesting that postsynaptic TrkB receptors are dispensable for LTP at the Schaffer collateral-CA1 synapses (Xu et al., 2000). Different LTP-inducing protocols are also modulated differentially by BDNF (Figurov et al., 1996; Kang et al., 1997; Patterson et al., 2001), and, therefore, the relative importance of presynaptic or postsynaptic TrkB receptors may vary accordingly.

Approximately half of TrkB-positive adult hippocampal nerve terminals were not stained with glutamatergic markers (Fig. 6, Table I). This suggests that non-glutamatergic synapses might also be possible targets for BDNF in the hippocampus. In fact, BDNF enhances acetylcholine release from adult hippocampal synaptosomes (Knipper et al., 1994), and reduces $\mathrm{GABA}_{\mathrm{A}}$-mediated inhibitory postsynaptic currents in adult hippocampal slices through presynaptic and postsynaptic mechanisms (Tanaka et al., 1997; Frerking et al., 1998; Olofsdotter et al., 2000). It would be interesting to investigate the percentage of cholinergic and GABAergic terminals that express TrkB.

In conclusion, our data show that only one-third of presynaptic glutamatergic nerve terminals express TrkB in the adult hippocampus. Within those terminals, an even lower percentage of this receptor is present at the plasma membrane, accessible to its ligands because $75 \%$ of fulllength TrkB receptors are located intracellularly. This implies that BDNF does not modulate neurotransmitter release in the majority of these terminals, supporting a restricted synapse-specific action of BDNF in the modulation of glutamate release. Further studies will be required to relate TrkB synapse-specific expression with the state of synapse maturation and long term synaptic strengthening.

\section{ACKNOWLEDGMENTS}

We would like to express our gratitude to Regeneron Pharmaceuticals Inc. (Tarrytown, NY) for providing us with BDNF, and to Dr. J. Blasi for the syntaxin $1 \mathrm{~A}$ antibody. We would also like to thank E. Carvalho for excellent technical assistance.

\section{REFERENCES}

Alder J, Thakker-Varia S, Crozier RA, Shaheen A, Plummer MR, Black IB. 2005. Early presynaptic and late postsynaptic components contribute independently to brain-derived neurotrophic factor-induced synaptic plasticity. J Neurosci 25:3080-3085.

Almeida RD, Manadas BJ, Melo CV, Gomes JR, Mendes CS, Graos MM, Carvalho RF, Carvalho AP, Duarte CB. 2005. Neuroprotection by BDNF against glutamate-induced apoptotic cell death is mediated by ERK and PI3-kinase pathways. Cell Death Differ 12:1329-1343.

Baxter GT, Radeke MJ, Kuo RC, Makrides V, Hinkle B, Hoang R, Medina-Selby A, Coit D, Valenzuela P, Feinstein SC. 1997. Signal transduction mediated by the truncated trkB receptor isoforms, trkB.T1 and trkB.T2. J Neurosci 17:2683-2690.

Berg MM, Sternberg DW, Parada LF, Chao MV. 1992. K-252a inhibits nerve growth factor-induced trk proto-oncogene tyrosine phosphorylation and kinase activity. J Biol Chem 267:13-16.

Berninger B, Schinder AF, Poo MM. 1999. Synaptic reliability correlates with reduced susceptibility to synaptic potentiation by brain-derived neurotrophic factor. Learn Mem 6:232-242.

Canas N, Pereira IT, Ribeiro JA, Sebastiao AM. 2004. Brain-derived neurotrophic factor facilitates glutamate and inhibits GABA release from hippocampal synaptosomes through different mechanisms. Brain Res 1016: 72-78.

Carmona MA, Martinez A, Soler A, Blasi J, Soriano E, Aguado F. 2003. $\mathrm{Ca}^{2+}$-evoked synaptic transmission and neurotransmitter receptor levels are impaired in the forebrain of trkb $(-/-)$ mice. Mol Cell Neurosci 22:210-226.

Chao MV. 2003. Neurotrophins and their receptors: a convergence point for many signalling pathways. Nat Rev Neurosci 4:299-309.

Diaz-Hernandez M, Pereira MF, Pintor J, Cunha RA, Ribeiro JA, Miras-Portugal MT. 2002. Modulation of the rat hippocampal dinucleotide receptor by adenosine receptor activation. J Pharmacol Exp Ther 301:441-450.

Drake CT, Milner TA, Patterson SL. 1999. Ultrastructural localization of full-length trkB immunoreactivity in rat hippocampus suggests multiple roles in modulating activity-dependent synaptic plasticity. J Neurosci 19: 8009-8026.

Du J, Feng L, Yang F, Lu B. 2000. Activity- and $\mathrm{Ca}^{2+}$-dependent modulation of surface expression of brain-derived neurotrophic factor receptors in hippocampal neurons. J Cell Biol 150:1423-1434.

Dunkley PR, Jarvie PE, Heath JW, Kidd GJ, Rostas JA. 1986. A rapid method for isolation of synaptosomes on Percoll gradients. Brain Res 372:115-129.

Ernfors P, Wetmore C, Olson L, Persson H. 1990. Identification of cells in rat brain and peripheral tissues expressing mRNA for members of the nerve growth factor family. Neuron 5:511-526.

Figurov A, Pozzo-Miller LD, Olafsson P, Wang T, Lu B. 1996. Regulation of synaptic responses to high-frequency stimulation and LTP by neurotrophins in the hippocampus. Nature 381:706-709.

Fremeau RT Jr, Troyer MD, Pahner I, Nygaard GO, Tran CH, Reimer RJ, Bellocchio EE, Fortin D, Storm-Mathisen J, Edwards RH. 2001. The expression of vesicular glutamate transporters defines two classes of excitatory synapse. Neuron 31:247-260.

Frerking M, Malenka RC, Nicoll RA. 1998. Brain-derived neurotrophic factor (BDNF) modulates inhibitory, but not excitatory, transmission in the CA1 region of the hippocampus. J Neurophysiol 80:3383-3386.

Gomes AR, Cunha P, Nuriya M, Faro CJ, Huganir RL, Pires EV, Carvalho AL, Duarte CB. 2004. Metabotropic glutamate and dopamine receptors co-regulate AMPA receptor activity through PKA in cultured chick retinal neurones: effect on GluR4 phosphorylation and surface expression. J Neurochem 90:673-682.

Goodman LJ, Valverde J, Lim F, Geschwind MD, Federoff HJ, Geller AI, Hefti F. 1996. Regulated release and polarized localization of brainderived neurotrophic factor in hippocampal neurons. Mol Cell Neurosci 7:222-238.

Gooney M, Lynch MA. 2001. Long-term potentiation in the dentate gyrus of the rat hippocampus is accompanied by brain-derived neurotrophic factor-induced activation of TrkB. J Neurochem 77:1198-1207. Gottschalk W, Pozzo-Miller LD, Figurov A, Lu B. 1998. Presynaptic modulation of synaptic transmission and plasticity by brain-derived neurotrophic factor in the developing hippocampus. J Neurosci 18:6830-6839. 
Hartmann M, Heumann R, Lessmann V. 2001. Synaptic secretion of BDNF after high-frequency stimulation of glutamatergic synapses. EMBO J 20:5887-5897.

Herzog E, Bellenchi GC, Gras C, Bernard V, Ravassard P, Bedet C, Gasnier B, Giros B, El Mestikawy S. 2001. The existence of a second vesicular glutamate transporter specifies subpopulations of glutamatergic neurons. J Neurosci 21:RC181.

Huang EJ, Reichardt LF. 2003. Trk receptors: roles in neuronal signal transduction. Annu Rev Biochem 72:609-642.

Jovanovic JN, Czernik AJ, Fienberg AA, Greengard P, Sihra TS. 2000. Synapsins as mediators of BDNF-enhanced neurotransmitter release. Nat Neurosci 3:323-329.

Kang H, Jia LZ, Suh KY, Tang L, Schuman EM. 1996. Determinants of BDNF-induced hippocampal synaptic plasticity: role of the Trk B receptor and the kinetics of neurotrophin delivery. Learn Mem 3:188196.

Kang H, Schuman EM. 1995. Long-lasting neurotrophin-induced enhancement of synaptic transmission in the adult hippocampus. Science 267: $1658-1662$.

Kang H, Welcher AA, Shelton D, Schuman EM. 1997. Neurotrophins and time: different roles for TrkB signaling in hippocampal long-term potentiation. Neuron 19:653-664.

Klein R, Conway D, Parada LF, Barbacid M. 1990. The trkB tyrosine protein kinase gene codes for a second neurogenic receptor that lacks the catalytic kinase domain. Cell 61:647-656.

Knipper M, da Penha Berzaghi M, Blochl A, Breer H, Thoenen H, Lindholm D. 1994. Positive feedback between acetylcholine and the neurotrophins nerve growth factor and brain-derived neurotrophic factor in the rat hippocampus. Eur J Neurosci 6:668-671.

Korte M, Griesbeck O, Gravel C, Carroll P, Staiger V, Thoenen H, Bonhoeffer T. 1996. Virus-mediated gene transfer into hippocampal CA1 region restores long-term potentiation in brain-derived neurotrophic factor mutant mice. Proc Natl Acad Sci USA 93:12547-12552.

Kossel AH, Cambridge SB, Wagner U, Bonhoeffer T. 2001. A caged Ab reveals an immediate/instructive effect of BDNF during hippocampal synaptic potentiation. Proc Natl Acad Sci USA 98:14702-14707.

Kovalchuk Y, Hanse E, Kafitz KW, Konnerth A. 2002. Postsynaptic Induction of BDNF-mediated long-term potentiation. Science 295:17291734.

Kryl D, Yacoubian T, Haapasalo A, Castren E, Lo D, Barker PA. 1999. Subcellular localization of full-length and truncated Trk receptor isoforms in polarized neurons and epithelial cells. J Neurosci 19:58235833.

Lamballe F, Klein R, Barbacid M. 1991. trkC, a new member of the trk family of tyrosine protein kinases, is a receptor for neurotrophin-3. Cell 66:967-979.

Lessmann V, Gottmann K, Heumann R. 1994. BDNF and NT-4/5 enhance glutamatergic synaptic transmission in cultured hippocampal neurones. Neuroreport 6:21-25.

Lessmann V, Heumann R. 1998. Modulation of unitary glutamatergic synapses by neurotrophin-4/5 or brain-derived neurotrophic factor in hippocampal microcultures: presynaptic enhancement depends on preestablished paired-pulse facilitation. Neuroscience 86:399-413.

Levine ES, Crozier RA, Black IB, Plummer MR. 1998. Brain-derived neurotrophic factor modulates hippocampal synaptic transmission by increasing N-methyl-D-aspartic acid receptor activity. Proc Natl Acad Sci USA 95:10235-10239.

Levine ES, Dreyfus CF, Black IB, Plummer MR. 1995. Brain-derived neurotrophic factor rapidly enhances synaptic transmission in hippocampal neurons via postsynaptic tyrosine kinase receptors. Proc Natl Acad Sci USA 92:8074-8077.

Li YX, Xu Y, Ju D, Lester HA, Davidson N, Schuman EM. 1998a. Expression of a dominant negative TrkB receptor, T1, reveals a requirement for presynaptic signaling in BDNF-induced synaptic potentiation in cultured hippocampal neurons. Proc Natl Acad Sci USA 95:1088410889.

Li YX, Zhang Y, Lester HA, Schuman EM, Davidson N. 1998 b. Enhancement of neurotransmitter release induced by brain-derived neurotrophic factor in cultured hippocampal neurons. J Neurosci 18:1023110240.

Lopes LV, Cunha RA, Kull B, Fredholm BB, Ribeiro JA. 2002. Adenosine $A_{2 A}$ receptor facilitation of hippocampal synaptic transmission is dependent on tonic $A_{1}$ receptor inhibition. Neuroscience 112:319-329.

Matsumoto T, Numakawa T, Adachi N, Yokomaku D, Yamagishi S, Takei N, Hatanaka H. 2001. Brain-derived neurotrophic factor enhances depolarization-evoked glutamate release in cultured cortical neurons. J Neurochem 79:522-530.

McMahon HT, Foran P, Dolly JO, Verhage M, Wiegant VM, Nicholls DG. 1992. Tetanus toxin and botulinum toxins type A and B inhibit glutamate, gamma-aminobutyric acid, aspartate, and met-enkephalin release from synaptosomes. Clues to the locus of action. J Biol Chem 267: 21338-21343.

Messaoudi E, Bardsen K, Srebro B, Bramham CR. 1998. Acute intrahippocampal infusion of BDNF induces lasting potentiation of synaptic transmission in the rat dentate gyrus. J Neurophysiol 79:496-499.

Messaoudi E, Ying SW, Kanhema T, Croll SD, Bramham CR. 2002. Brain-derived neurotrophic factor triggers transcription-dependent, late phase long-term potentiation in vivo. J Neurosci 22:7453-7461.

Meyer-Franke A, Wilkinson GA, Kruttgen A, Hu M, Munro E, Hanson MG, Jr., Reichardt LF, Barres BA. 1998. Depolarization and cAMP elevation rapidly recruit TrkB to the plasma membrane of CNS neurons. Neuron 21:681-693.

Minichiello L, Korte M, Wolfer D, Kuhn R, Unsicker K, Cestari V, RossiArnaud C, Lipp HP, Bonhoeffer T, Klein R. 1999. Essential role for TrkB receptors in hippocampus-mediated learning. Neuron 24:401-414.

Olofsdotter K, Lindvall O, Asztely F. 2000. Increased synaptic inhibition in dentate gyrus of mice with reduced levels of endogenous brainderived neurotrophic factor. Neuroscience 101:531-539.

Patterson SL, Abel T, Deuel TA, Martin KC, Rose JC, Kandel ER. 1996. Recombinant BDNF rescues deficits in basal synaptic transmission and hippocampal LTP in BDNF knockout mice. Neuron 16: 1137-1145.

Patterson SL, Grover LM, Schwartzkroin PA, Bothwell M. 1992. Neurotrophin expression in rat hippocampal slices: a stimulus paradigm inducing LTP in CA1 evokes increases in BDNF and NT-3 mRNAs. Neuron 9:1081-1088.

Patterson SL, Pittenger C, Morozov A, Martin KC, Scanlin H, Drake C, Kandel ER. 2001. Some forms of cAMP-mediated long-lasting potentiation are associated with release of BDNF and nuclear translocation of phospho-MAP kinase. Neuron 32:123-140.

Pereira DB, Carvalho AP, Duarte CB. 2002. Non-specific effects of the MEK inhibitors PD098, 059 and U0126 on glutamate release from hippocampal synaptosomes. Neuropharmacology 42:9-19.

Phillips GR, Huang JK, Wang Y, Tanaka H, Shapiro L, Zhang W, Shan WS, Arndt K, Frank M, Gordon RE, Gawinowicz MA, Zhao Y, Colman DR. 2001. The presynaptic particle web: ultrastructure, composition, dissolution, and reconstitution. Neuron 32:63-77.

Pinheiro PS, Rodrigues RJ, Silva AP, Cunha RA, Oliveira CR, Malva JO. 2003. Solubilization and immunological identification of presynaptic alpha-amino-3-hydroxy-5-methyl-4-isoxazolepropionic acid receptors in the rat hippocampus. Neurosci Lett 336:97-100.

Poo MM. 2001. Neurotrophins as synaptic modulators. Nat Rev Neurosci 2:24-32.

Pozzo-Miller LD, Gottschalk W, Zhang L, McDermott K, Du J, Gopalakrishnan R, Oho C, Sheng ZH, Lu B. 1999. Impairments in highfrequency transmission, synaptic vesicle docking, and synaptic protein distribution in the hippocampus of BDNF knockout mice. J Neurosci 19:4972-4983. 
Rebola N, Pinheiro PC, Oliveira CR, Malva JO, Cunha RA. 2003. Subcellular localization of adenosine $A_{1}$ receptors in nerve terminals and synapses of the rat hippocampus. Brain Res 987:49-58.

Rodrigues RJ, Almeida T, Richardson PJ, Oliveira CR, Cunha RA 2005. Dual presynaptic control by ATP of glutamate release via facilitatory $\mathrm{P} 2 \mathrm{X}_{1}, \mathrm{P}_{2} \mathrm{X}_{2 / 3}$, and $\mathrm{P} 2 \mathrm{X}_{3}$ and inhibitory $\mathrm{P} 2 \mathrm{Y}_{1}, \mathrm{P}_{2} \mathrm{Y}_{2}$, and/or $\mathrm{P} 2 \mathrm{Y}_{4}$ receptors in the rat hippocampus. J Neurosci 25:6286-6295.

Rose CR, Blum R, Pichler B, Lepier A, Kafitz KW, Konnerth A. 2003. Truncated TrkB-T1 mediates neurotrophin-evoked calcium signalling in glia cells. Nature 426:74-78.

Schinder AF, Berninger B, Poo M. 2000. Postsynaptic target specificity of neurotrophin-induced presynaptic potentiation. Neuron 25:151-163.

Schuman EM. 1999. Neurotrophin regulation of synaptic transmission. Curr Opin Neurobiol 9:105-109.

Smith PK, Krohn RI, Hermanson GT, Mallia AK, Gartner FH, Provenzano MD, Fujimoto EK, Goeke NM, Olson BJ, Klenk DC. 1985. Measurement of protein using bicinchoninic acid. Anal Biochem 150: 76-85.

Takamori S, Rhee JS, Rosenmund C, Jahn R. 2000. Identification of a vesicular glutamate transporter that defines a glutamatergic phenotype in neurons. Nature 407:189-194.

Takamori S, Rhee JS, Rosenmund C, Jahn R. 2001. Identification of differentiation-associated brain-specific phosphate transporter as a second vesicular glutamate transporter (VGLUT2). J Neurosci 21: RC182.
Tanaka T, Saito H, Matsuki N. 1997. Inhibition of $\mathrm{GABA}_{\mathrm{A}}$ synaptic responses by brain-derived neurotrophic factor (BDNF) in rat hippocampus. J Neurosci 17:2959-2966.

Tapley P, Lamballe F, Barbacid M. 1992. K252a is a selective inhibitor of the tyrosine protein kinase activity of the trk family of oncogenes and neurotrophin receptors. Oncogene 7:371-381.

Tartaglia N, Du J, Tyler WJ, Neale E, Pozzo-Miller L, Lu B. 2001. Protein synthesis-dependent and -independent regulation of hippocampal synapses by brain-derived neurotrophic factor. J Biol Chem 276:3758537593.

Tyler WJ, Pozzo-Miller LD. 2001. BDNF enhances quantal neurotransmitter release and increases the number of docked vesicles at the active zones of hippocampal excitatory synapses. J Neurosci 21:4249-4258.

Xu B, Gottschalk W, Chow A, Wilson RI, Schnell E, Zang K, Wang D, Nicoll RA, Lu B, Reichardt LF. 2000. The role of brain-derived neurotrophic factor receptors in the mature hippocampus: modulation of long-term potentiation through a presynaptic mechanism involving TrkB. J Neurosci 20:6888-6897.

Yacoubian TA, Lo DC. 2000. Truncated and full-length TrkB receptors regulate distinct modes of dendritic growth. Nat Neurosci 3:342-349.

Ying SW, Futter M, Rosenblum K, Webber MJ, Hunt SP, Bliss TV, Bramham CR. 2002. Brain-derived neurotrophic factor induces longterm potentiation in intact adult hippocampus: requirement for ERK activation coupled to CREB and upregulation of Arc synthesis. J Neurosci 22:1532-1540. 